\title{
HYDROTHERAPY AQUATIC PHYSIOTHERAPY AND THE APPLICATION OF BAD RAGAZ RING METHOD
}

\author{
Timothy Ainslie ${ }^{1}$
}

${ }^{1}$ MSc, Biomechanics Strathclyde University, CTHE Member of Manual Therapy Association of Chartered Physiotherapists (MMACP), Graduate Diploma Physiotherapy, Chartered Society of Physiotherapy. Senior Lecturer:Department of Sport and Health Sciences, Faculty of Health and Life Sciences, "Oxford Brookes" University (Oxford-UK).

KEYWORDS: Hydrotherapy, Physiotherapy, Rehabilitation, Physical Therapy Technique,

\section{ABSTRACT}

This paper reviews the use of water-based therapy to rehabilitate patients with deficits of functional movement or muscle control. The properties of water are described and their relevance to the application of treatment techniques to patients in a therapy pool. The physiological effects of being immersed in water are described with reference to treatment application. It is important to ensure that the contraindications and precautions are considered before a patient can enter a therapy pool. A specific approach to rehabilitation of patients in a therapy pool utilising the Bad Ragaz Ring Method is outlined, with examples being given of how this approach may be used in the rehabilitation of patients.

\section{INTRODUCTION}

The Roman Empire saw the advent of 'Sanus per Aquam' or Spa baths, with them being used in a therapeutic manner to recuperate wounded legionnaires. Galen (130-200 A.D) one of the forefathers of medicine undertook studies of the properties and effects of water and with others developed this into a science (Hajar, 2012).

With the demise of the Roman Empire there was little further development until the Renaissance in the 15th and 16th Centuries (Hajar, 2012).

By this point of view, Vincent Priessnitz , 1799-1851 may be considered as the father of the modern hydrotherapy (immersion of the body in thermal water for therapeutic purposes) and one of the originators of naturopathic medicine and balneotherapy (medicinal use of thermal water) (Metcalfe, 2012)

Spas became popular throughout America and Europe becoming centres for the new social elites emerging along with the industrial revolution (Gianfaldoni et al., 2017).

The twenty first century has seen water therapy establish its role in modern healthcare provision with water-based therapy providing physical, psychological benefits as well as being a relaxing experience (Gianfaldoni et al., 2017).

In the United Kingdom in the 1930s The Chartered Society of Physiotherapy in conjunction with Rheumatologists began to train physiotherapists to treat patients with Rheumatological diseases. Roman Spas such as Bath, became acknowledged centres of thermal aquatic therapy (Ainslie, 2012).

During the same period German doctor H. Knupfner began using a method of treatment where a therapist worked in water with patients to produce changes in muscle tone (Knupfner, 1956). Polio epidemics in America in the 1940s and 1950s led to the proprioceptive neuromuscular facilitation (PNF) techniques developed by Knott and Voss in Vallejo California that became integral part of rehabilitation in the 1960 s (Voss et al., 1985).

In Bad Ragaz Switzerland during the 1960s the physicians and therapists WM Zinn, Nele Ipsen and Bridget Davies and Beatrice Egger published articles outlining the Bad Ragaz ring method (BRRM) drawing upon the work of Knupfer, Knott and Voss. These techniques utilise the water properties of turbulence and streamlining, using buoyancy for support. Techniques are applied utilising physiological movement of joints and muscles in functional patterns (Ainslie, 2012).

Contemporary Aquatic Physiotherapy should form a part of a patient pathway where rehabilitation is necessary. It may be delivered as a sole treatment or as part of a treatment package complimenting other interventions.

Cardiorespiratory endurance, muscle strength, flexibility, balance, functional capacity and psychological considerations may benefit from treatments provided in a therapy pool (Templeton et al.,1996; Hinman et al., 2007; Wang et al., 2007).

A good knowledge of the physical properties of water and the skills to utilise these properties to create effective treatments are prerequisites for therapists using water as a therapeutic medium.

There is a danger of water-based therapies becoming marginalised in the modern health systems due to economic pressures. Teaching time devoted to the theory and practical application of hydrotherapy has been eroded on physical therapy programmes. Hospitals and centres look at hydrotherapy as being an expensive resource that often becomes subject to cutbacks when financial savings have to be made. It is essential that therapists are aware of the benefits of water based therapy and that further evidence is generated to justify the use of hydrotherapy /aquatic physiotherapy as a necessary part of the rehabilitation options available to treat patients (Cole \& Becker, 2010). 


\section{THE PROPERTIES OF WATER}

\section{Hydrostatic Pressure}

The pressure of water exerted on a body immersed up to the level of $\mathrm{C} 7$ will lead to decreased diastolic blood pressure, increased systolic volume, increased venous return to the right side of the heart and increased renal function. Factors that need to be considered when a patient is being assessed for suitability for aquatic therapy. Expiratory reserve volume decreases, vital capacity decreases and lung compliance is reduced meaning precautions should be taken for patients with compromised lung function (Hellsten et al., 2012).

\section{Relative Density of Water}

The average human body with air in the lungs will float with $2.5 \%$ of its volume out of the water. As muscle bulk increases so the body becomes denser and less buoyant. Males tend to have greater muscle mass then women and therefore float less easily. With old age bone and muscle mass decreases and therefore the body will be more buoyant. In application the legs tend to sink into the water while the trunk floats (Brody \& Geigle, 2009).

\section{Buoyancy}

Archimedes principle states that a body totally or partially immersed in a fluid is subject to an upward force equal in magnitude to the weight of fluid it displaces. A person standing immersed to the xiphisternum experiences $70 \%$ weight relief and to C7 $90 \%$ weight relief (Harrison \& Bulstrode, 2009)

A person with a slight build will have their centre of buoyancy close to the centre of gravity so will be stable, whereas a person who is obese, with a large abdomen will tend to fall backwards and have legs that will float to the surface more easily. A muscular person will tend to have legs that sink to the bottom of the water.

\section{Turbulence}

Turbulence can be utilised as a resistance to movement. As a body moves through water it leaves an area of low pressure behind the body that creates a drag (resistance)to the movement of the body through the water. The amount of turbulence may be influenced by the surface area presented by the body, thus the more streamlined the body the less drag will be created behind it. The velocity of movement will also influence the amount of turbulence and therefore the amount of resistance to movement.

\section{Refraction}

The light passing from air into the water will be distorted by the denser water. This means it is difficult to evaluate movement of a limb and its correct position in the water.

\section{CONTRAINDICATIONS AND PRE CAUTIONS FOR HYDROTHERAPY AQUATIC PHYSIOTHERAPY}

All patients should have a comprehensive assessment, part of which will assess the suitability of the patient for this intervention and will include screening for contraindications and precautions. These are divided into absolute contraindications (Table 1), relative contraindications and precautions and acted upon accordingly.
Relative contraindications: Patients with the following conditions require further consideration considering the risk/benefit analysis, but if hydrotherapy/ aquatic therapy is considered this should be done so cautiously (Table 2)

Precautions Patients with the following may receive hydrotherapy/aquatic therapy but additional precautions may be required (Table 3 )

Considerations The following additional factors should be taken into consideration during treatment planning and participation (Table 4).

\section{BAD RAGAZ RING METHOD (BRRM)}

These techniques are applied with one therapist working with a single patient in the water.

All patients are assessed for suitability for aquatic therapy ensuring all contraindications and precautions are accounted for and in addition the planned treatment should avoid fatigue, which is easily reached in patients who are in poor general physical condition. The therapist should be aware of the patient getting dizzy due to the vestibular stimulus generated through the patient's body movements. Care should be taken when treating patients with neurological conditions where active or resisted exercise may increase spasticity.

As with PNF techniques BBRM uses functional patterns of movement, these patterns may be applied bilaterally or as unilateral techniques. Short concise verbal commands are given by the therapist. Maximal resistance is used, and weak muscles are recruited by overflow from stronger muscles (Adler et al., 2008). PNF is different to BRRM, in that PNF requires the therapist to move with the working part of the body, whereas with BRRM the body moves through the water as a result of the manual force applied by the therapist, where the therapist is the fixed point.

Patients tend to be positioned in supine or side lying and may be provided with floatation aids such as a neck collar or a waist float to maintain the body at the water's surface, with floats being attached to wrists or ankles as necessary. The floats assist the therapist in maintaining the patient's position to enable the desired movements to be applied to their body.

The therapist maintains a stable stance in the water with their feet at least a shoulders width apart, the water level should be up to the therapist's axillae, with the therapist maintaining contact with the patient at all times, this is especially important where the patient may be anxious about being immersed in water.

\section{PRINCIPLES OF APPLICATION OF BRRM}

BRRM method advocates using isometric patterns to manage pain with movement being in pain free range. Treatment will aim to increase joint range of movement, improve muscle power and endurance, relieve pain, restore normal patterns of movement, and improve the patient's confidence (Taunton et al., 1996; Omar et al., 2019).

Generally, treatment for trunk weakness or pain is begun using limb patterns. In the case of patients demonstrating anxiety about being immersed in water the therapist will begin with hold that are proximal to the body, near the patient's head.

As treatment is progressed the levers can be length- 


\begin{tabular}{|l|l|}
\hline Tab.1 - Absolute contraindications to hydrotherapy / aquatic therapy \\
\hline Acute systemic pathology & Emesis e dysentery \\
\hline Clinical instability due to acute episodes & Allergy to chlorine and bromine \\
\hline Angina at rest & Breathlessness at rest \\
\hline $\begin{array}{l}\text { Uncontrolled cardiac insufficiency / paroxysmal noc- } \\
\text { turnal dyspnea }\end{array}$ & Infected wounds \\
\hline $\begin{array}{l}\text { HIV or hepatitis C positive people (should not enter in } \\
\text { water during menstrual cycle) }\end{array}$ & \\
\hline
\end{tabular}

\begin{tabular}{|l|l|}
\hline Tab. 2 - Relative contraindications to hydrotherapy / aquatic therapy \\
\hline Patients undergoing radiation therapy & Aneurysm \\
\hline Open wounds & Uncontrolled epilepsy \\
\hline Unstable diabetes & Thyroid deficit \\
\hline Neutropenia & Artificial oxygenation necessity \\
\hline $\begin{array}{l}\text { Bodyweight exceeding the maximum load of safety } \\
\text { facilities }\end{array}$ & \\
\hline
\end{tabular}

\begin{tabular}{|l|l|}
\hline Tab. 3 - Precautions to hydrotherapy / aquatic therapy \\
\hline Urinary or fecal incontinence & Severe obesity \\
\hline Epilepsy & Haemophilia \\
\hline Staphilococcus infection & Ipotension \\
\hline Renal insufficiency & Cutaneous pathologies or surgical / open wounds \\
\hline Pregnancy (if water temperature is higher than $\left.35^{\circ} \mathrm{C}\right)$ & Invasive pathologies \\
\hline Aspiration risk & Reduced caloric provision \\
\hline Syncope & Sickle cell anemia \\
\hline Inefficient thermoregulation & Tracheostomy \\
\hline Fungal infection & Episodes of disreflexyia \\
\hline Fear of water & Aggressive or unpredictable behavior \\
\hline Congiuntivitis or contact lenses & Acoustic pathology \\
\hline Vision alteration & \\
\hline
\end{tabular}

Tab. 4 - Conditions to take into account while planning a session of hydrotherapy / aquatic therapy

\begin{tabular}{|l|l|}
\hline Shortness of breath during under exertion & Dizziness / Nausea / Syncope \\
\hline $\begin{array}{l}\text { Multiple sclerosis (in particular for patients with high } \\
\text { sensitivity to high temperatures) }\end{array}$ & Language problems \\
\hline Psoriasis / Sensitivity to cutaneous disinfectant & Warts / Tinea pedis \\
\hline
\end{tabular}

ened by the therapist changing their position to hold the upper or lower limbs more distally.

Duration of the treatment will begin initially with between 5-10 minutes of BRRM techniques, with patient fatigue being monitored. It is surprisingly tiring receiving BRRM treatments and the duration of the treatment session can be gradually increased according to the response of the patient up to 20 minutes of a 30-minute session of immersion in a therapy pool.

\section{Conditions indicated for BBRM}

Most orthopaedic or rheumatological conditions, for example: rheumatoid arthritis, osteoarthritis, pre and post-surgery, post fracture, neurological conditions such as post CVA or post spinal cord injury.

\section{Progression of BRRM exercises}

Increase speed of movement of the patient through the water.
Make the patient less streamlined, by adding floats or changing the shape of their body exposed to the water. The therapist can increase the lever arm by grasping the patient more distally.

Sudden change of direction of movement, so patient has to work against the water resistance and turbulence created by the sudden change of direction.

\section{Example of bilateral pattern BRRM technique (Hip abduction)}

Patient supported by neck and waist floats, lying supine with the therapist placing their hands on the lateral aspect of both ankles. At the start of the pattern the patient's feet will be just in front of the therapist The patient is instructed to abduct both hips, while the therapist provides a resistance, guiding both legs into internal rotation and extension at both hips.

The patient will finish with their hips abducted, internally rotated, and extended and their knees being at 
the therapists' sides. The therapist steps back to bring the patient's legs into the starting position with the patient's feet in front of them once more.

\section{CONCLUSION}

Aquatic physiotherapy is a means of treating patients with a variety of conditions that cause them to have pain, weakness, joint hypo-mobility, and loss of functional movement patterns. The properties of the water are utilised to provide graded rehabilitation for patients in a way that is difficult to replicate through land-based interventions. This paper has specifically explored the use of Bad Ragaz Ring Method as a treatment approach incorporating the properties of water that can be applied effectively to improve functional mobility and muscle function with patients in a heated therapy pool.

\section{Funding}

This research received no grant from any funding agency in the public, commercial, or not-for-profit sectors.

\section{Competing Interest}

The authors declared no potential conflicts of interest with respect to the research, authorship, and/or publication of this article.

\section{REFERENCES}

1. Adler, S. S., Beckers, D., \& Buck, M. (2007). PNF in practice: an illustrated guide. Springer Science \& Business Media.

2. Ainslie,T. R. (2012). The Concise Guide to Physiotherapy-Volumes 1 and 2. Oxford:Churchill Livingstone.

3. Brody, L. T., \& Geigle, P. R. (2009). Aquatic exercise for rehabilitation and training. Human Kinetics.

4. Cole, A. J., \& Becker, B. E. (Eds.). (2004). Comprehensive aquatic therapy. Butterworth-Heinemann.

5. Gianfaldoni, S., Tchemev, G., Wollina,U., Roccia, M. G., Fioranelli, M., Gianfaldoni, R., Lotti, T. (2017). History of the Baths and Thermal Medicine. Open Access Macedonian Journal of Medical Sciences, 5 (4), 566-568.

6. Hajar, R. (2012). The air of history: early medicine to Galen (part I). Heart views: the official journal of the Gulf Heart Association, 13(3), 120.

7. Harrison, R., \& Bulstrode, S. (1987). Percentage weight-bearing during partial immersion in the hydrotherapy pool. Physiotherapy Practice, 3(2), 60-63.

8. Hellsten, Y., Nyberg, M., Jensen, L. G., Mortensen, S. P. (2012). Vasodilator interactions in skeletal muscle blood flow regulation. Journal of Physiology, 590(24), 6297-6305.

9. Hinman, R. S., Heywood, S. E., Day, A. R. (2007). Aquatic physical therapy for hip and knee osteoarthritis: results of a single blind randomized controlled trial. Physical Therapy, 87(1), 32-36.

10. Knupfer, H. (1956). The therapeutic indications of underwater gymnastics. Die Medizinische, 7(27-28), 990-993.

11. Metcalfe, R. L. (2012). Life of Vincent Priessnitz, founder of hydropathy. Miami: Hardpress Publishing.

12. Omar, J. S., Khasati, A., Qadoumi, A. N., Quadoumi, M., Jarada, T. N. (2019). Watermelon juice and aquatic exercises, their synergistic effect on some physical fitness and physiological variables in males and females volunteers. Journal of research in pharmacy, 23(3), 387-394.

13. Taunton, J., Rhodes, E., Wolski, L., Donelly, M., Warren, J., Elliot, J., McFarlane, L., Leslie, J., Mitchell, J., Lauridsen, B. (1996). Effect of land-based and water-based fitness programs on the cardiovascular fitness, strength and flexibility of women aged 65-75 years. Gerontology, 42(4), 204-210.

14. Templeton, M. S., Booth, D. L., O'Kelly, W. D. (1996). Effects of aquatic therapy on joint flexibility and functional ability in subjects with rheumatic disease. Journal of Orthopaedic Sports Physical Therapy, 23(6), 376-381.

15. Voss, D. E., Ionta, M. K., Myers, B. J., \& Knott, M. (1985). Proprioceptive neuromuscular facilitation: patterns and techniques (pp. 298-311). Philadelphia, PA: Harper \& Row.

16. Wales Physiotherapy Advisory Group, (WPhLAG). (2016). All Wales Evidence Based Guidance for Access to Hydrotherapy for NHS Patients in Wales. December.

17. Wang, T. J., Belza, B., Thompson, E. F., Whitney, J. D., Bennett, K. (2007). Effects of aquatic exercise on flexibility, strength and aerobic fitness in adults with osteoarthritis of the hip or knee. Journal of Advanced Nursing, 57(2), 141152. 